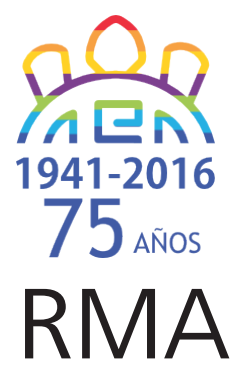

Antropología Social

\title{
Estilos de percepción de la biodiversidad y su conservación en actores sociales de áreas protegidas de Córdoba
}

\author{
Styles of perception of biodiversity and its conservation \\ by social actors in protected areas of Córdoba \\ Gustavo J. Martínez* y Jessica Manzano-García**
}

* IDACOR-CONICET, Museo de Antropología, Facultad de Filosofía y Humanidades,
Universidad Nacional de Córdoba, Argentina. E-mail: gustmart@yahoo.com.
** IDACOR-CONICET, Museo de Antropología, Facultad de Filosofía y Humanidades, Universidad Nacional de Córdoba, Argentina.

\begin{abstract}
Resumen
Se propone interpretar las percepciones locales relacionadas con la biodiversidad y su conservación en tres áreas protegidas de las Sierras de Córdoba. La información se obtuvo de técnicas de investigación etnoecológica, registros de observación participante, entrevistas en profundidad, encuestas semi-estructuradas y talleres participativos. Desde un punto de vista cualitativo se abordan narrativas en las que se evidencian pluralidad de percepciones vinculadas con problemáticas ambientales y con la importancia, conservación, retracción y/o control de especies. El análisis de sus contenidos revela la coexistencia de estilos perceptuales, asociados con diferentes perfiles de actores sociales. Esto se hace particularmente manifiesto en aspectos como: la identificación de especies problemáticas y emblemáticas; la valoración de los animales domésticos y de la práctica ganadera; las representaciones acerca de las invasiones biológicas; y los criterios de relevancia y utilidad de taxones nativos e introducidos. Asimismo, mediante Análisis de Correspondencia Múltiple (ACM) se dio cuenta de diferentes estilos de percibir y valorar los paisajes de ambientes serranos. Finalmente se discuten las significaciones y matices que adoptan las concepciones de lo nativo/exótico, lo doméstico/salvaje, lo extinto/invasor-plaga, en ámbitos de conservación en las que convergen múltiples experiencias culturales.
\end{abstract}

Palabras claves: etnoecología; percepción ambiental; conservación.

\begin{abstract}
This study aims at interpreting local perceptions related to biodiversity and its conservation in three protected areas of Sierras de Córdoba. The information was gathered from ethnoecological approaches, participant observation, in-depth interviews, semi-structured surveys and participatory workshops. From a qualitative viewpoint, we deal with narratives in which a plurality of perceptions is revealed in relation to environmental issues and the significance, conservation, retraction and/or control of species. Such analysis discloses the coexistence of styles of perception associated with the different profiles of social actors. This is particularly evident in the identification of emblematic and problematic species; the evaluation of domestic animals and livestock practice; the representation of biological invasion; and the criteria of relevance and usefulness for native and foreign taxa. In addition, a Multiple Correspondence Analysis (MCA) accounts for different styles of perceiving and appreciating the landscape of mountain environments. We also discuss the meanings and nuances that mold the conceptions of what is native and exotic, domestic and wild, extinct and invader-pest, in conservation areas where multiple cultural experiences converge.
\end{abstract}

Keywords: ethnoecology; environmental perception; conservation.

\section{Introducción a la problemática de las percepciones locales}

La comprensión de los procesos de percepción ambiental constituye un valioso recurso para un apropiado desarrollo de estrategias de conservación y desarrollo sustentable. El análisis del conocimiento y las percepciones locales en relación con los cambios medioambientales y la biodiversidad resulta revelador, no sólo de cómo evolucionan los ecosistemas, sino también de cómo las poblaciones locales experimentan cambios como parte $o$ en respuesta a éstos, y cómo diferentes factores afectan esta respuesta con respecto a la utilización de los recursos (Wiersum 1997). Asimismo, las percepciones ambientales 
-i.e. aquellos aspectos que los seres humanos aprecian, valoran o significan acerca de su entorno- configuran un corpus valioso de conocimientos y prácticas que aporta información de base e idiosincrática acerca de las problemáticas del ambiente, los cambios ecosistémicos, la biodiversidad y otros tópicos de la conservación (Fernández-Moreno 2008). Desde la mirada antropológica, se trata un tópico amplio, complejo y polarizado por la diversidad de enfoques teóricos y conceptuales. Acuñaremos en este trabajo la conceptualización que desde la antropología mexicana hace Durand (2008) de las percepciones, considerándolas procesos sociales de asignación de significados a los elementos del entorno natural y a sus cursos de transformación y/o deterioro. En búsqueda de incluir la dimensión de la acción, se ha sugerido asimismo incorporar a la percepción la noción de interpretación ambiental, dando paso así al concepto de "perspectivas ambientales"; éstas últimas definidas como "el conjunto de normas, supuestos y valores que resultan de la vivencia del entorno natural y permiten comprenderlo y explicarlo" (Durand 2008).

La percepción acerca de los cambios ambientales ha sido motivo de investigación y análisis en poblaciones indígenas y campesinas de Latinoamérica y del mundo, dando cuenta de la existencia de diversidad de perspectivas ambientales en relación con variables personales (como la trayectoria personal e histórica en relación con el entorno), socioculturales (como la división del trabajo de acuerdo al género), económicas y hasta políticas (Barri 2012). Entre los tópicos a los que estos estudios hacen referencia encontramos: las variaciones de la biodiversidad y provisión de servicios ecosistémicos en ambientes transformados; las significaciones locales de los seres vivos del entorno; las prioridades locales de conservación; las transformaciones en la vida cotidiana por cambios en la disponibilidad de recursos; el desplazamiento de saberes locales por conocimientos técnicos-científicos; y la transformación de un modelo basado en el aprovechamiento de recursos, a un proceso de patrimonialización de la naturaleza en prácticas y políticas conservacionistas de áreas protegidas (Santamarina-Campos y Bodí 2012).

Si particularizamos el análisis de las políticas de gestión de áreas protegidas, constatamos que los conocimientos, percepciones, necesidades y prácticas de los pobladores locales, suelen relegarse o estar ausentes a la hora de formular orientaciones y/o pautas de manejo y conservación, las que por lo general se construyen en forma monolítica y hegemónica. Un análisis histórico indica que no fue sino hasta los años noventa que se tomaron en consideración los costos políticos, económicos sociales y ecológicos de la aplicación de modelos rígidos e intolerantes que excluían a las poblaciones locales de sus territorios. Fue así que la necesidad de participación local en la protección del ambiente se convirtió en un asunto primordial de las áreas protegidas donde las poblaciones locales mantienen sus derechos sobre la tierra, subsistencia y autodeterminación. De esta manera adquieren relevancia las ideas sobre participación social y desarrollo sustentable en áreas protegidas. En la actualidad se reconoce a las poblaciones locales por contar con un conocimiento medioambiental que podría ser aprovechado en beneficio de la conservación. Un análisis antropológico detallado y un amplio listado de referencias autorales de los efectos sociales, económicos y políticos de proyectos de conservación ambiental en áreas protegidas puede consultarse en la revisión de West et al. (2006). El mismo examina las áreas protegidas como formas de ser, comprender y producir naturaleza (ambiente) y cultura (sociedad) y como forma de gestionar y controlar la relación entre ambos. Analiza asimismo la violencia, conflictos, relaciones de poder y gobernabilidad en tanto están conectadas con los procesos de protección de estas áreas.

De más reciente data, la incorporación de la perspectiva etnoecológica (Berkes et al. 2000; Berkes 2011; Rist y Dahdouh-Guebas 2006), permite problematizar la integración y/o visión de la dimensión sociocultural en el ámbito de la ecología y en este sentido, generar propuestas más incluyentes. Asimismo alienta a reflexionar acerca de la imbricada trama entre naturaleza y cultura, promoviendo una mayor vinculación entre la conservación ecológica y cultural (Fernández-Moreno 2008). Este enfoque, sin embargo, ha sido escasamente explorado en nuestro país, aún en regiones como el centro de Argentina, en las que el cambio histórico en la cobertura boscosa por intensificación del uso de suelos, así como del impacto socioambiental de la agriculturización -por citar algunas problemáticas relevantes de esta región- impactan directamente en la disponibilidad y aprovechamiento de la biodiversidad y otros recursos naturales (Zak et al. 2008; Cáceres et al. 2010).

Para el caso particular de las sierras de Córdoba, la drástica reducción del bosque y de sus servicios ecosistémicos, constituye una problemática de gran magnitud; así lo evidencia el hecho que al presente, queda menos de un $5 \%$ de la superficie boscosa original en la provincia de Córdoba, y los bosques serranos se perdieron a una tasa anual de 9,4\% (Gavier y Bucher 2004; Zak et al. $2004,2008)$. Esta situación, junto a otros motivos, ha suscitado el interés de investigadores locales en el estudio de estos ambientes, dando lugar a una nutrida producción científica especialmente en el campo de la ecología vegetal y de la fitogeografía de Córdoba, que aportan información valiosa para la conservación de estas regiones. En contraste con la profusión de estudios ecológicos, las investigaciones de índole socioantropológica y etnobiológica vinculadas a la conservación de áreas naturales, resultan inusuales. Sí en cambio se conocen estudios de etnobiología relacionados con la percepción ambiental, entre ellos los trabajo de Suárez 
(2014), Richeri et al. (2012, 2013) y Trillo et al. (2014, 2016). Asimismo, hasta el momento desconocemos, para nuestro país, abordajes que consideran los diferentes estilos de percepción ambiental de la biodiversidad en actores sociales de áreas protegidas.

En este trabajo nos proponemos comprender cómo los actores locales perciben e interpretan en general la práctica de la conservación, y en particular las problemáticas vinculadas a cambios en el paisaje o en los patrones de vegetación (pérdida del bosque nativo y la biodiversidad, invasiones biológicas), retracción de especies, y las consecuencias en su vida cotidiana de éstos y otros procesos.

En este sentido procuramos indagar las percepciones locales acerca de la biodiversidad en las diferentes áreas protegidas, considerando una doble perspectiva cualitativa y cuantitativa. En relación con la primera tomaremos narrativas y reconstrucciones históricoambientales de los pobladores en áreas protegidas de las sierras de Córdoba y, con la segunda, nos aproximaremos a un análisis multidimensional de la cultura. Proponemos para ello una exploración guiados por las siguientes problemáticas: ¿Cómo se vinculan los diferentes actores sociales de áreas protegidas con la biodiversidad local? ¿Qué peculiaridades presentan las percepciones o miradas locales acerca de la flora y fauna en cada uno de ellos? ¿Qué orientaciones o aportes provee el análisis de estas percepciones a la conservación y el manejo de especies en las áreas de estudio?

En particular, tomaremos como referencia teórica, los estudios de percepción y cambio ambiental en poblaciones locales (Fernández-Moreno 2008; Durand 2008; Seidi et al. 2011), y aquéllos que se abordan desde la perspectiva etnoecológica (Berkes 2011; Santamarina-Campos \& Bodí 2012). Asimismo, consideramos fecundo pensar los tópicos de ambiente, biodiversidad y conservación a la luz de los de "estilos de pensar" de Douglas (1998) y de las nociones y modelos de relación naturaleza-sociedad de Descola y Pãlsson (2001).

\section{Consideraciones Metodológicas}

\section{Áreas y población de estudio}

La mayoría de las sierras de Córdoba, pertenecen al Distrito fitogeográfico del Chaco Serrano, de la Provincia Chaqueña según Cabrera (1994), o a la subárea homónima de la ecorregión del Chaco Seco según el criterio de Torrella y Adámoli (2005). El presente trabajo se llevó a cabo en tres áreas protegidas de las serranías de Córdoba, con características diferenciadas en relación con las prácticas de conservación, uso y manejo de sus recursos naturales, así como de la población vinculada a las mismas y su historia ambiental. Estas son: 1) Reserva Hídrica Natural Bamba y áreas aledañas (RHNB): Un área protegida declarada formalmente pero sin historia ni práctica de manejo, ubicada en el sector de Sierras Chicas; 2) Reserva Natural Comunal La Rancherita (RCLR): Área de reciente creación y en proceso de reglamentación y manejo, ubicada en el Valle de Paravachasca; 3) Parque Nacional Quebrada del Condorito (PNQC): Con amplia trayectoria de gestión de la conservación y uso de sus recursos, localizada en el sector de Sierras Grandes. Más detalles de estos ambientes, su problemática y población pueden consultarse en Palacios et al. (2010), Fernández et al. (2013) y Manzano-García (2013).

\section{Obtención y análisis de información}

En el desarrollo metodológico se combinaron metodologías de las ciencias sociales y naturales, propias de los enfoques etnoecológicos (Cunningham 2001; Anderson et al. 2011), recurriendo para ello a técnicas y análisis cualitativos y cuantitativos (estadística multivariada).

El abordaje metodológico mixto (de análisis cuali cuantitativo) requirió del empleo de información de campo de primera mano, la que se obtuvo por medio de:

a) Encuestas semi-estructuradas.

b) Entrevistas abiertas, extensas y en profundidad a entrevistados claves.

c) Observación participante.

d) Registros etnográficos de cuadernos de campo y archivos sonoros previamente generados en las regiones de estudio.

e) Bases de datos etnobotánicas y de material documental vegetal de las sierras de Córdoba, las que cuentan con información de primera mano obtenida desde el año 2001 y hasta el presente.

En relación con el muestreo, se tuvieron en cuenta las consideraciones y peculiaridades propias de un estudio social de tipo exploratorio, procurando obtener información panorámica para eventuales indagaciones en profundidad. Para ello consideramos oportuno la realización de un muestreo no probabilístico, con las siguientes características:

- Muestreo de oportunidad, intencional o de conveniencia, y por técnica de bola de nieve para la selección de entrevistados e informantes, procurando dar cuenta de la diversidad de puntos de vistas y actores para el conjunto de las áreas protegidas.

- En relación con las encuestas semi-estructuradas, para definir el tamaño de muestra se siguió el criterio de saturación de información, evitando la redundancia, y procurando representar la diversidad de actores y sus perspectivas de conservación y vinculación con la biodiversidad. Para ello se aplicaron un total de 55 encuestas semi-estructuradas en diferentes unidades domésticas de las tres áreas. A los fines de una mayor especificidad analítica, y sobre la base de una 
caracterización demográfica y cultural previa de los entrevistados, se definieron tres tipologías de actores sociales a saber: a) Población nativa (PN): Población originaria del lugar o con mucha antigüedad, campesinas o con vinculación al presente de actividades de subsistencia (campesino) o en pasado reciente (descampesinizado); b) Población foránea o neorrural (PF): Población no nativa proveniente de ámbitos urbanos, residente de pocos años, temporal o esporádico, no campesina; c) Otros actores (OA): Actores externos radicados en el área y vinculados a organismos de conservación y grupos ambientalistas locales, o bien a emprendimientos inmobiliarios, turísticos, entidades gubernamentales/estatales. A su vez se tuvo en cuenta en los análisis la caracterización socioeconómica, para lo cual del continuum de capitalización económica se delimitaron dos categorías polares: Mayor capitalización (C) y menor capitalización, con presencia de rasgos de economía de subsistencia (S).

- Se amplió la base de datos acerca de las especies biológicas con información complementaria proveniente de 10 entrevistas abiertas en profundidad.

Desde el punto de vista metodológico se consideraron los siguientes análisis de la información:

a) Análisis cualitativos: Se adoptó como enfoque de trabajo la perspectiva inductiva de la "teoría fundamentada", "muestreo teórico" o "grounded theory" (Glaser y Strauss 1967). Para ello se transcribieron y analizaron narrativas, fragmentos de discurso o expresiones de las entrevistas abiertas, los que fueron luego codificados de acuerdo con categorías temáticas emergentes (principales y subsidiarias) que dieran cuenta de la percepción acerca de las problemáticas ambientales y del cambio ambiental en relación con las especies de la biodiversidad local (e.g., motivos, magnitud, cambios históricos y diacrónicos, significación, etc.).

b) Análisis cuantitativos: Para la interpretación de la percepción del paisaje a partir de estímulos visuales (elección de fotografías), se aplicaron Análisis de Correspondencia Múltiple, según detallaremos más adelante. Se escogió esta técnica estadística para el tratamiento de las encuestas semi-estructuradas, siguiendo la metodología de Bourdieu (2012) que muestra gráficamente lo multidimensional de la cultura, en un mapa de posiciones sociales y de preferencias de consumo.

\section{Análisis cualitativo de las percepciones sobre el ambiente y sus problemáticas}

En este apartado haremos referencia a dos de las problemáticas que surgieron en forma recurrente y de manera ostensible en las narrativas: los incendios y el manejo ganadero.

En general los pobladores neorrurales, como los que habitan en La Rancherita, dan cuenta de los embates del fuego y de sus consecuencias nefastas en el ámbito de la reserva. Sin embargo, entre los nativos campesinos ganaderos, existe cierta valoración positiva respecto del uso del fuego controlado, como forma de manejo de la vegetación.

"O sea llegaba, ponéle en junio, julio, agosto vos decías, quiero quemar toda aquella parte; vos agarrabas esta línea da alambre, y aquella, y lo limpiabas a $3 \mathrm{~m}$ de distancia del alambre, que no quede ni un pastoreo. Entonces vos llegabas, le prendías fuego. Se quemaba todo alrededor y el alambre no se te quemaba; porque si no, se te va el fuego por cualquier lado...

E: Era beneficioso?

C: Si porque limpiabas el campo, después Ilovía y te venía un pasto nuevo, un pastoreo hermoso... Porque ya estaba muy viejo y muy acamado el pasto viejo ahí; entonces Ilovía, venía el pasto nuevo y el pasto viejo, no era bueno; entonces llega una cierta cantidad de años que vos lo tenés que limpiar a eso, por las garrapatas, por todo eso; por el parásito por todo eso, lo limpiás al campo, por eso lo quemás. Pero la gente lo iba quemando por parte, ¿me explico? No que voy a quemar todo eso y le prendí fuego acá que se quemó; no, era por parte y a su mediado tiempo, no tampoco en cualquier tiempo."

(C., Poblador nativo Pje. Casa Bamba, RHNB;)

Asimismo, advierten acerca de la importancia del manejo de la carga ganadera de un área, como práctica de prevención de incendios.

(S) "Y eso la gente del campo sabe que sin yuyo el fuego no corre.

(R) Acá está lleno de yuyo y no se puede ni andar.

(C) Cuando nosotros teníamos animales, como las vacas, desde acá veíamos toda la cañada. ¡Mirá ahora! No se ve nada.

(R) De acá hasta San Clemente no hay ni una vaca, así que está lleno de yuyo.

(S) Pero antes cuando nosotros íbamos andaban las vacas por la calle, porque ahora está más poblado.

(R) Antes no había qué quemarse, pero ahora se quema todo porque tenés pasto hasta en tu patio. Entonces por eso allá en la Rancherita han largado animales, para que pisen el suelo y maten un poco de plantas y así no hay tantos incendios. Porque si hay pasto el fuego corre más rápido en cambio sí está más limpio se corta un poco el fuego"

(Familia A., Poblador nativo La Rancherita, $\mathrm{RCLR}$;)

En los relatos anteriores resultan recurrentes los términos 
o derivaciones de "fuego", "quemar", "pastos" y "yuyos" que aparecen como categorías temáticas subsidiarias en el discurso de los nativos a la hora de abordar la problemática ambiental de los incendios. El fuego, en el primero de los casos, está visto como forma de limpieza de los campos; el segundo texto pone en juego tres factores que se encuentran en tensión en la ecología: la importancia de la biomasa de las pasturas, su relación con la herbivoría y la carga ganadera, y la propagación de los incendios. De hecho, y tal como lo señalan Cingolani et al. (2008), en sistemas que evolucionaron con altas presiones de herbívoros, ya sean domésticos o silvestres, la ganadería a cargas comerciales puede ser compatible con la conservación, y aún necesaria. Asimismo, los entrevistados se hacen eco de un conocimiento ecológico académico que refiere cómo la ganadería también produce efectos indirectos tales como la reducción de la frecuencia de fuegos espontáneos en sistemas semiáridos, asociada a la disminución de la biomasa combustible. Sin embargo, y en contraste, en sistemas húmedos y subhúmedos, es común el desmonte y aumento antropogénico de la frecuencia de fuegos para habilitar y mantener tierras aptas para el ganado.

El impacto de la ganadería en las áreas de estudio constituye otra de las problemáticas percibida en forma distinta por los diferentes actores, influyendo en esto la trayectoria y el perfil socioeconómico-productivo del entrevistado.

Por lo general, los pobladores ganaderos se manifiestan renuentes a las restricciones de cría de animales en las áreas protegidas, resaltando los beneficios ambientales de esta actividad y minimizando cualquier tipo de perjuicio. De hecho, la prohibición del uso de un sitio que otrora estuvo destinado a la ganadería, como el PNQC, es significado como la transformación en un territorio no-vital, estéril o muerto, y a nivel socioeconómico, el paso a un estilo de vida de no-trabajo. Esta percepción, la significación afectiva y emocional del ganado para el lugareño, así como las significaciones acerca de la cría de animales domésticos, en comparación con la fauna silvestre, quedan de manifiesto en los siguientes testimonios:

"El Parque Nacional (Quebrada del Condorito) se creó en el 82, hasta esa época yo trabajé ahí. Y en el 82 ya empezaron a sacar los animales, pum, paf, y se armó el Parque Nacional. Y se hicieron una, dos, tres estancias, Parque Nacional... pero terribles estancias! Habian estancias de 7000 hectáreas, 10 mil hectáreas, otra de 12 mil hectáreas. Sabe la gente que se quedó sin el pan?, y todas trabajaban para la estancia?! En la Estancia La Trinidad se llegó a tener iii12 mi ovejas!!! Sabe los empleados que habían ahí para las esquilas? Y después fue quedando en nada, pum paf, ¿por qué? Porque la lana no valía, el cuero no valía, entonces la gente pum!, dijo no, hasta acá llego. Y así se fue terminando todo, de a poco a poco, y ahora los vivientes de ahí vecinos no pueden tener animales porque se los comen los pumas. Ahí desde que se armó Parque Nacional no han dejado entrar más a nadie. Y acá al Norte de Quebrada del Condorito, pusieron guardias, están los guarda-parques que vos vas ahí y vos querés ir a ver la Quebrada del Condorito hay un guía que te lleva y te trae.

...Truchas, digamos, toda cuestión de eso, había cualquier cantidad y no te dejaban entrar a pescar más. Eso todo lo que es el Parque.

$Y$ es una zona que lo único que tiene es animales silvestres, de ahí no tiene más nada. No tiene cabras, no tiene ovejas, no tiene vacas, no tiene caballos, no tiene nada... iiY sabe qué estancias que había!! ¡Qué cascos de estancias que había! Tenía equipo de radio, de teléfono. Yo hablo en el tiempo en que se trabajaba. Y eso quedó porque era todo hecho de material, las viviendas están... Hay gente que lo ve de una forma, pero el que no conoce bien lo ve de una forma distinta. Pero el tipo que lo ha conocido ahí no, vos pasás ahí y te da pena... pensás que acá había tantos animales, iy hoy no hay nada! Vos pasás en Pampa de Achala, vos pasás con el colectivo, con el auto por la ruta, había vacas, icabras, vacas y ovejas de los dos lados de la ruta! Ahora pasás ahí, y no ves nada, campo y campo y campo... y aparte esos campos no son para sembrarlos ni nada de eso, porque no sirven para siembra; entonces eso es para pastoreo nada más. No es como para acá para el lado de Córdoba, que decís, bueno no le meto vaca, le meto siembra; pero allá no podés, no podés hacer. Con decirte que no podés hacer ni una quinta, porque por ahí cae un hielo y te quema todo; es muy distinto el clima de allá a acá"

(C., antiguo poblador del PNQC) "...Que haiga como antes... Antes ese campo, habrá querido ver ese tiempo! Cuando nosotros recién vinimos acá, no? Había ¿sabe qué?, la cantidad de burros... Había muchísimas cabras del monte, en el campo éste; había liones (=pumas), había zorros, todo bicho, sabe la cantidad de animal que había acá! Perdices había muchísima, y se empezaron a perder, que la empezaron a cazar; chancho del monte todo eso había. Y ahora hay chancho del monte todavía; acá por éste campo."

(P. Poblador nativo Villa El Diquecito, RHNB)

El primero de los relatos da cuenta de que la creación de áreas protegidas como el PNQC se resuelve en lapsos breves de tiempo y de manera abrupta ("pum paf, y se armó el parque nacional; y se hicieron, una dos tres estancias"), y no como un proceso gradual. 
Asimismo comienza a darse un mayor control sobre las actividades que allí se realizan debido a la injerencia de nuevos actores, como los guardaparques. Queda también evidenciado en el discurso una insistente referencia al contraste de épocas, entre lo que "había" o fue en el pasado, y las transformaciones acontecidas en el presente. Todo esto expresa cambios importantes en las prácticas, en los aspectos productivos y políticos de manejo de estas regiones, lo que da lugar a nuevas representaciones acerca de su rol y de sus características.

Por su parte, los pobladores que antaño disponían de ganado, a raíz de un cambio en su perfil socioeconómico, por ejemplo por inserción en áreas protegidas en carácter de guarda-parques, asocian la carga ganadera con la pérdida del suelo, el avance de los procesos erosivos y, en general con una disminución de la sustentabilidad ambiental. Así lo pone de manifiesto el siguiente fragmento de un poblador nativo que trabaja para el Parque Nacional Quebrada del Condorito en el que se advierte un discurso adquirido de las capacitaciones locales para el ejercicio de su nuevo rol:

"Con la ganadería, se va perdiendo el suelo, con el tiempo hace daño, la tierra cava mucho, después vienen las lluvias y se lleva el suelo, se va viendo cada vez más la piedra, se va acabando... se podría tratar que la gente pueda tener sólo cierta cantidad de animales por hectárea para que la hectárea se conserve.... Con el tema del parque se da uno cuenta, que hay adelantos, en el mismo Condorito... las plantas como los animales se la comían y se va terminando... la cabra es muy, pero muy dañina, todo lo que ella come por ahi se seca... Hay mucha gente que vive solamente de los animales, ¿cómo le haces entender a esa gente que tiene que sacar lo animales, porque le está haciendo daño al suelo?"

(V., Poblador nativo PNQC)

No obstante, y a pesar de que hay una valoración positiva de estas nuevas formas de trabajo remuneradas -sobre todo por considerarlo un trabajo "más liviano"- se entretejen junto a este discurso ecológico, expresiones de añoranza por los tiempos pretéritos. Éste se manifiesta en la significación afectiva que estos actores siguen dando a los animales domésticos y a la actividad ganadera, en una matriz cultural que recibió el impacto, al menos en lo discursivo, de las profundas modificaciones devenidas de la implementación del área protegida.

"-_le gustaría retomar las actividades anteriores... como establecer otra vez sus animales (ganadería)?- y si a volver... que te permitieran a volver, pero eso es imposible, no creo que vuelva, pero si poder digamos, que se yo?, digamos no sé, como ahora ya cambió, lo que pasa es que por ahí uno se va dando cuenta de cosas, que por ahí hay cosas que tienen razón, que por ahi como son los animales, te llevan el suelo... por ahí que se yo? También ahora está más peligroso por los incendios, si se prende fuego, si se prendía fuego antes lo apagabas en cualquier lado, ahora tenés que andar bastante para apagar un fuego y más con los pastos... según yo hay cosas que te favorecen y hay cosas que no, está bien tienen gente...., ¿ cómo se dice?, especializada en eso, pero son cosas a favor, hay cosas en contra". (I., Poblador nativo PNQC)

\section{Análisis cualitativo de las percepciones locales acerca de la biodiversidad}

En la exposición de este punto consideramos los siguientes aspectos y categorías temáticas:

\section{a) Importancia y conservación}

El análisis del contenido de las entrevistas abiertas en relación con la importancia de la flora local pone de relieve cómo los pobladores campesinos valoran las plantas, fundamentalmente por la utilidad que éstas proveen. Los ámbitos que mayor interés concitan son el de las plantas medicinales y de las combustibles por la provisión de leña, así lo ponen de manifiesto la cantidad de especies y usos compilados in situ en nuestras bases de datos. Expresiones como "linda leña", "leña buena y fuerte", o "no voy al médico tengo yuyos medicinales" se reiteran en gran parte de los entrevistados.

Por su parte se observa una ostensible declinación en el uso de plantas silvestres comestibles, particularmente entre los pobladores nativos. Por el contrario, en RCLR, se constata un interés de la población neorrural por enriquecer la alimentación cotidiana con "malezas comestibles" como el diente de león (Taraxacum officinale), la verdolaga (Portulaca oleracea) y otras que expresan modalidades de apropiación simbólica de saberes ecológicos por parte de estos actores. Esta práctica también ha sido referida entre pobladores del sur de Argentina (Bariloche, Río Negro), en una investigación que no sólo documentó sino también, por medio de talleres, promovió la recuperación y la innovación en el uso de malezas como alimento y medicinas (Ladio et al 2013). Se trata en todos los casos, tal como lo señala Trimano (2015), de pobladores que deciden trasladar su lugar de residencia de la ciudad al campo impulsados por la necesidad de exaltar la naturaleza por oposición al mundo artificial de las ciudades, logrando una adscripción al mundo rural mediante una red de prácticas orientadas al bienestar integral, que incluyen la dietética.

En contraste, los pobladores foráneos y otros actores especialmente aquellos vinculados a la práctica de la conservación, enfatizan la importancia de especies nativas 
por su función ecológica (menor consumo de agua, capacidad de restaurar cuencas, adaptación al lugar), así como por su belleza paisajística, y la posibilidad de mantener las cualidades prístinas de un sitio natural.

Aun cuando no fueron señaladas como prioritarias para conservar, las entrevistas y las narrativas pusieron de relieve, en forma insistente, la relevancia cultural de especies de importancia etnobotánica local que actualmente se encuentran en retracción debido a los cambios ambientales, particularmente por "la seca" o "sequía". Se señala por ejemplo el progresivo deterioro de los árboles de coco (Zanthoxylum coco) y, junto a ello, una importante merma de algunos recursos que otrora tuvieran relevancia alimenticia y para la economía doméstica, como los hongos de coco y molle (Phlebopus bruchii):

"Hay muy poco coco, se ha caído muy mucho... oh antes había mucho, juntábamos los hongos bajo los cocos, bajo los molles; ahora ya no hay, se han secado muchísimo los cocos, se están perdiendo...no sé por qué será? Acá se están perdiendo mucho los cocos... hay una planta rara que se consigue acá. Se van secando, se secan... yo no sé por qué será? Yo sé que el coco se está perdiendo. Acá en estos campos había coco hasta decir basta! Yo los otros días le decía a los chicos, qué raro que no hay coco; porque en las quebradas asi había mucho, vio? Están secos, todos, una que otra plantita si encuentra de coco; el coco es bueno para hacer madera vio? Porque un coco no es dura la madera para cortar....para trabajarla, como hacer cucharas, esas cosas vio? Es muy cómodo para trabajarla.../ Antes se hacían esas cosas, cucharitas, hacíamos para mover las cosas. Como leña es muy flojo..... da mucho humo y se apaga muy rápido y hace mucha cenizas...."

No hay hongos, antes se vendía mucho el hongo, uhh. Se ganaba mucho con el hongo antes, pero ahora ya no, no hay. Nosotros teníamos en Calera unos señores que compraban, ya han muerto; o si no lo llevábamos a Córdoba. Nosotros solíamos hacer escabeches de hongos; se los hacía para el asado, con cebolla, todo así vio?, ajo, cositas que den gusto; echaban un perejil bien picado; después echábamos unas hojitas de romero asi nomás, sin picarlo para que se sienta bien el gusto."

(P., Poblador nativo Villa El Diquecito, RHNB)

"R: Ahora fui a buscar hongos y no encontré.... Porque si no hay sol, el hongo no nace y el bosque de yuyos es muy alto y abajo no llega el sol.... Yo le he juntado por años, 5 mil hasta $10 \mathrm{mil} k \mathrm{~kg}$, a Cingolani.

S: Antes vivíamos en Potrerillo y juntábamos...
Hacian conservas.

R: En Potrerillo. Yo pagaba por kg a personas para que los juntaran, después los hervía y los ponía en salmuera. Después venían y los buscaban. Y lo llevaban a Córdoba... Nosotros se los mandábamos en salmuera y lo pagaban bien pagados.

$\mathrm{CH}$ : Nosotros teníamos ollas grandes, acá queda una!.

R: Estábamos todas las noches cocinando.

E: ¿Y eso era en qué época?

R: En los 70... (Ahora) se ve que nadie junta...El del Molle era más caro.

S: Pero aparte, al hongo lo cortas y lo vendes seco. CH: Sí, el hongo del molle y coco seco, son carísimo. El del pino mucho no lo quieren."

(Familia A., Poblador nativo La Rancherita, RCLR)

En relación con los animales existe un consenso y valoración general de todos los actores respecto de las aves. La población nativa, valora especialmente en sus narrativas, las especies aprovechables de fauna acuática (aves y peces). En este sentido los informantes, al referir información minuciosa acerca de su presencia, habituación, práctica de captura y/o consumo dan cuenta de un conocimiento preciso acerca de su valor en tanto indicadores de diversidad y/o calidad del agua, o como un recurso alimenticio que deviene de las prácticas de recolección, caza y/o pesca, tal como lo denotan las menciones de este poblador nativo, al referir especies de importancia:

"D: zorzales, alondra, mandioca gato, semillero, jilguero, brasita, hay poco zorzal, ahora hay chalchalero.... Treintipico de años acá

$R$ : Estamos siempre acá, yo siempre he sido del campo

D: (Yo) pesco, no cazo!

F: hace como cuatro años apareció la tararira, yo antes pescaba pejerrey, carpa, moncholo, mojarrita, dientudo".

(D., R. y F. Pobladores nativos El Diquecito, RHNB)

"El águila (mora) equilibra el tema de las ratas, las víboras... mantiene el equilibrio digamos y en el caso del cóndor es el que mantiene limpio el terreno, ese no deja nada, todo bicho que muere el cóndor lo limpia, el caso del águila es de rapiña -mata-, en cambio el otro se alimenta de lo que está muerto, cumplen dos funciones distintas".

(D. Poblador nativo, PNQC)

\section{b) Retracción de especies}

En relación con los cambios en la abundancia y/o retracción de las especies nativas, las narrativas dan cuenta de la percepción de múltiples causas, las que resultan específicas según el tipo de especie de la que se 
trate. La pérdida de especies arbóreas, por ejemplo se asocian fundamentalmente a la tala indiscriminada para fines múltiples como el empleo de algarrobo (Prosopis spp.) en mueblería y leña, el uso histórico del quebracho (Schinopsis lorentzii) en hornos de cal en Bamba y el coco (Zanthoxylum coco) para fuego de hornos. Asimismo en las herbáceas o arbustivas de interés medicinal, impactarían entre otros factores, los cambios en el patrón de uso de los suelos y el manejo ganadero que afectan la composición florística; asimismo la forma y magnitud de extracción con fines comerciales o de uso doméstico, esto especialmente señalado para el caso de la peperina (Minthostachys verticillata), el tomillo serrano (Hedeoma multiflora) y la cola de quirquincho (Huperzia saururus).

"D: La única que sabía traer yo así del campo, peperina, la contrahierba que le dicen es una que echa las hojas grandecitas verdes, pulmonaria sabía haber antes, pero se han secado por la sequía...

R: Había mucho algarrobo!... hay una familia que cortó como cuatro... luego dejaron de cortar porque nosotros empezamos a hablar, lo usaban para hacer muebles. Sabía haber montón de árboles.... Han dejado uno solo -allá- arriba.

$R$ : La peperina, el suico, el paico, contrahierba, la hierba del sapo hay poca... la gente la junta y la arranca a la peperina... por la loma había plantas de ruda..

$D$ : se secó todo!

R: la hierba del carnicero, hay más por la vía... servía para el hígado para el estómago.. la pasionaria también hay mucha

$R$ : la peperina es una que ha desaparecido más

$R$ : la carqueja, antes había más, la de hoja ancha... la, carquejilla -la de hoja fina-... de eso hay poca!... como ahora no hay tanta agua en el campo, en las lomas por eso van desapareciendo .... Después el que las junta, las arranca; cabotoril aún hay... en el barrio de piedra...

D: a ese (cabotoril) hay que buscarlo con lupa."

(D. y R., Pobladores nativos El Diquecito, RHNB)

"E: ¿Qué plantas fueron desapareciendo?

CH: Todas, como: la peperina, doradilla, cancha del agua, el quiebra-arau, mata pulga, palo amarillo.

R: Pero no es que se hayan perdido porque se perdieron, sino que hay otros yuyos que se han invadido o sobrepuesto y han matado a todos los demás. Hoy fui a buscar hongos, y vi que para aquel lado hay vacas y otros animales. La vaca comen pastito y matan el yuyo... entonces allá hay mata pulga, hay de todo. Y como acá no hay animales por eso están desapareciendo esas plantas, porque hay mucho de esos yuyos que impiden que crezcan otros. Hay muchos yuyos que los siembran los animales como el caballo y la vaca."

(Flia. A., Poblador nativo La Rancherita, RCLR)

"Esos árboles altos que se ven ahí al frente, son quebrachos; ahi solía haber mucha peperina, pero éste año había poca. Nosotros antes juntábamos yuyos para vender con mi cuñado, vendíamos todos esos yuyos; peperina sabía vender camionadas, que ahora la gente isabe lo que hacia? La arrancaba y la peperina hay que quebrarla más que arrancarla, porque si usted la arranca se pierde todo... así que la gente y esa gente yuyeros que andan juntando, todo las arrancan. Mire que antes había el palo amarillo, ese eran campos también, ahora están pocos; también hay pocos esas cosas; el manzano del campo antes era muchísimo, había; ahora también todas esas cosas se están perdiendo, piquillín, el manzano del campo...el quebracho blanco antes había mucho, se hachaba para los hornos de cal..."

(P., Poblador nativo Villa El Diquecito, RHNB)

En relación con la fauna, entrevistados de las inmediaciones de la Reserva Bamba, dan cuenta también de cambios recientes en la biodiversidad ictícola asociado a la calidad del agua del Río Suquía, así como la desaparición de aves debido al tráfico y comercialización ilegal:

"D: Sí, pescaba antes... había mucho moncholo, ahora hay tararira, ahora no existe la palometa, hay pocas carpas... por el agua, falta de oxígeno... hay mucho biguá que se come el pescado (chico)...

La tararira o pescado negro, no sé de dónde vino, tiene buena carne pero mucha espina... el pejerrey ya no viene porque no hay creciente... (Antes) había muchas mojarra, (pero) el biguá no deja nada."

"R: Los zorzales, la alondra (es azul, más chiquita que el zorzal) no se ve más... el zorzal mandioca, está por la quebrada de la Usina (al frente de la Usina) ya no se puede andar por el campo como antes...........

D: los semilleros hay, pero los entrampan mucho $R$ : acá cerca hay una casa donde los entrampan! $D$ : bueno, dejálos! ¡Ellos vivirán de eso!

$R$ : ahora dicen que tienen más, los roban en las casas

D: acá lo único que entrampan son pájaros!

D: Jilgueritos, la brasita, semilleros...

E: Brasitas hay todavía, carpinteros ya no hay como antes

$R$ : Las calandrias no vienen más!"

(D. y R., Pobladores nativos El Diquecito, RHNB)

En todos los casos, la presión sobre las especies, tal como lo señalan Lichtenstein \& Carmanchahi (2014) atentan no 
sólo contra la biodiversidad, sino contra los valores locales y medios de vida de personas que viven en situación de pobreza y que dependen del uso de los recursos. Es así que al perderse los recursos se pierden también saberes, prácticas, y las construcciones locales de la naturaleza. Una de las respuestas a ello es el uso sustentable de una especie silvestre, la que debería contemplar los aspectos ambientales, económicos y sociales; éstos últimos puede ser favorecer una mejor distribución de beneficios en la cadena de producción y comercialización, evitar la degradación ambiental y afianzar o recuperar pautas culturales del uso de la biodiversidad. Respecto de esto se conocen para nuestra provincia experiencias de desarrollo sustentable de algunas de las especies que aparecen en forma recurrente en las narrativas. Por ejemplo, la presión por el uso y comercialización de la "peperina" (Minthostachys mollis) -una de las más citadas- dio lugar a la protección de la misma por medio de ensayos de domesticación y producción en cultivo (Ojeda et al. 2015).

\section{c) Control y/o eliminación de especies}

La percepción de las plantas exóticas e "invasoras" -categoría frecuentemente utilizada en ecología- no resulta uniforme entre los actores, advirtiéndose como en otros tópicos, divergencias y tensiones entre los diferentes discursos.

Entre los pobladores nativos, por ejemplo, resulta habitual la referencia y valoración de algunas exóticas e "invasoras" en función de los servicios ecosistémicos que éstas aportan.

Son especialmente valoradas aquellas que proveen sombra -como el paraíso (Melia azedarach), la mora (Morus spp.), la higuerilla (Broussonetia papyrifera)-, recursos para la cultura material (varillas), especies forrajeras como el siempre verde (Ligustrum lucidum) y el paraíso, y aún por su valor ornamental como el crataegus (Pyracantha spp.) del que se proveen de gajos para multiplicar en los jardines como cerco o "adorno". Asimismo al indagar sobre la temática algunos pobladores campesinos refieren como invasoras o necesarias de control a algunas especies autóctonas como la tusca (Acacia aroma) o el espinillo (Acacia caven) que afectan la práctica de la ganadería.

"Yo creo que la razón que se están extinguiendo muchas plantas autóctonas, como ser la misma peperina, el mismo tomillo, es que está siendo atacada por varios tipos de hormiguitas; parece que no fuera cierto, pero la realidad es que las plantas están mostrando que algo pasa y que al contrario, pienso que las plantas como ser el paraíso, las plantas invasoras que le llaman, la mora, el siempreverde; mirá alrededor Gustavo, mirá alrededor! Imagínate si no tuviera ese paraíso, estas moras, fíjate esas plantas invasoras, qué habría? Sería un monte pobre...
Entonces para mí no es tan importante esto de las plantas invasoras y no de estas peleas estúpidas que hay...porque viste que hay unos naturalistas que dicen, no porque las plantas, éste que.... Cuando se trata de forestar y eso. Yo creo que lo primero que tendrían que hacer es ver por qué se están muriendo las plantas autóctonas! Si vos analizás bien las cuestiones, la misma mora tiene su atacante ¿sabías vos eso?"

(L., Otros actores Pje. Boca Dos, RHNB)

"El paraíso, es fuertísimo para poste"

(P., Poblador nativo Villa El Diquecito, RHNB)

"Sabe que planta ha cundido? El espinillo y la tusca...Porque antes había chivas, la misma chiva la ha sembrado... come el algarrobo, la chaucha... ya no se puede andar casi en el campo"

(R., Poblador nativo, El Diquecito, RHNB)

"Una planta que prosperó mucho es el siempreverde. Es útil para los pájaros, tiene hoja todo el año y se cobija mucho la palomita chiquita gris... el grateus lo lleva el zorzal, es vistoso de adorno...es bueno para cerco"

(H., Poblador foráneo El Diquecito, RHNB)

Contrastan los testimonios anteriores con los de la población de RCLR, en su mayoría foránea y con un perfil socioeconómico en el que se advierte un proceso de instrucción formal más consolidado. Con un discurso más próximo al de la ecología académica, subrayan la distinción entre nativo y exótico, y dan cuenta de su impacto diferencial en relación con el consumo de agua, y la importancia de controlar estas últimas para evitar invasiones biológicas. Así lo indican los resultados de talleres participativos realizados durante el 2012 en la comuna en los que se señaló como problemático el avance del lirio acuático (Iris pseudoacorus) sobre el cauce del arroyo, o la dispersión de especies de crataegus (Pyracantha spp.) y acacia negra (Gleditsia triacanthos), oportunidad en la que se propusieron medidas de control y eliminación de algunas de ellas.

"Para leña me proveo de plantas que no son de acá, paraíso, olmos y acacia negra que es plaga..."

(H., Poblador foráneo La Rancherita, RCLR) "Hay juncos y yuyos que retiene mucho el agua, se forma barro... Era muy hermoso ese lugar. Podría restaurarse por el potencial turístico. Cuando salís de la reserva y empieza el cauce, caminando para las cascadas pasas de todo nativo a todo exótico. Es otro paisaje! De lirio está lleno... acacia negra, juncos. Y está lleno de el de bolitas rojas (crataegus)... No podés pasar... hay veces que no se ve el río. Hay algo de ganado en esa zona pero 
cada vez menos porque no le pueden dar agua. En Villa Giardino usan el lirio amarillo para curar el agua... pero acá esta descontrolado... Habría que controlar las exóticas, cambiar poquito a poco".

(Participantes del III Taller Enraizando

Paravachasca, Otros actores, RCLR)

Cualquiera sea el punto de vista ambiental de los actores, se ha señalado que las especies exóticas invasoras, son la segunda causa de amenaza y extinción de especies precedida por la pérdida del hábitat y seguida del comercio ilegal (Jaquenod De Zsögön, 2014), lo que da cuenta de la relevancia de esta problemática.

El carácter de invasivo, según las narrativas considera especies "que no son de acá" o "que cunden" o "prosperan" dando cuenta de que predomina un criterio fitogeográfico y otro de abundancia ecológica; por el contrario no aparecen en las narrativas, referencias a mecanismos reproductivos y formas de propagación de las especies, un aspecto clave para comprender el problema de las invasiones. Esto indica que las percepciones locales de un fenómeno ecológico como las invasiones, no responden a los mismos criterios de la ecología académica.

En relación con las especies invasoras, las narrativas remarcan que, a pesar de que se reconoce su importante impacto en el paisaje, ecosistemas y niveles de biodiversidad, no todos los impactos son negativos, ya que las especies exóticas invasoras brindan a las poblaciones locales, tanto costos como beneficios. Como resultado del crecimiento poblacional de estas especies, pueden llegar a constituir la base de muchos sistemas de manejo de recursos económicamente importantes, tales como agricultura, horticultura, forestación y paisajes ornamentales o de jardines. En este sentido, las invasiones biológicas por especies exóticas deben evaluarse no sólo desde el punto de vista de la sustentabilidad ecológica, sino también socioambiental para lo cual hay que valorar la relación costo beneficio (Bardsley y Edwards-Jones, 2006). A pesar de la importancia económica de muchas especies invasoras, al presente la mayoría de los trabajos publicados se han centrado en los aspectos biológicos de las invasiones. Esto sin embargo no es suficiente, ya que los procesos de invasión por especies exóticas son tanto un proceso natural como social. De hecho, las personas realizan elecciones que aumentan o disminuyen las chances de que una especie se transforme en invasora. Estos relatos muestran precisamente la dimensión social de estos procesos.

En lo concerniente a la fauna, muchas de las especies con valoración negativa, son aquellas que de alguna manera afectan procesos socio-económicos productivos. Tal es el caso del zorro (Pseudalopex griseus) y el puma (Puma concolor), cuya acción predatoria sobre el ganado y/o en la cría de animales domésticos (aves de corral) produce aversión en buena parte de los pobladores nativos; en claro contraste y oposición, otros actores (con miradas ambientalistas) y los pobladores foráneos, manifiestan un marcado interés por su conservación.

En particular y para el puma, Sillero (2000) define la interacción con el poblador rural, como una relación de conflicto en la que es adjetivado como una especie perjudicial, debido a la depredación de animales domésticos, o por el consumo de especies silvestres que coinciden en la dieta de ambos (Ojasti, 1984). Por lo anterior, se hace necesario comprender la visión del nativo, en la que el cuidado de los animales domésticos, como el ganado, adopta una significación afectiva y emocional (Le Breton 2012), inherente a su cultura. A continuación, dos fragmentos de relatos que refleja ambas formas de percepción:

"(El puma) Nos guste o no, es de la zona" (J. N. Poblador foráneo, Pje. Casa Bamba, RHNB) "El puma, que sabemos que pasa, pero no lo vemos, normalmente de noche, isabemos que pasa por qué bueno acá al frente está el puesto Pedernera digamos y sabemos que a veces tienen algún problema con el puma que le come algún ternero u oveja, por donde pasa exactamente? No sabemos... El problema del puma en realidad que tiene con los puesteros es cuando le enseña a cazar a la cría, le mata capaz veinte corderos -y no los come- es para enseñarle a matar a la cría nada más" (D. Poblador nativo, PNQC)

Otras de las especies poco toleradas por pobladores nativos y campesinos por el "daño" que causan, a cultivares o frutales, son las loras (Myiopsitta monahcus) o en algunos casos las palomas (Zenaida auriculata y Columba livia). Por el contrario, los pobladores foráneos no demuestran un rechazo tan marcado hacia estas especies, sino que adoptan actitudes de benevolencia. Los siguientes relatos dan cuenta de algunas de estas percepciones:

"Los cacholotes son dañinos, ahora las loritas hay muchas, han cundido mucho... las loritas, las catas, hace unos años es que han empezado a cundir... 10 años más o menos!

(D. y R., Pobladores nativos El Diquecito, RHNB)

"(El zorro) Sólo trae daños, mata corderos y gallinas"

(R. y E., Pobladores nativos Villa El Diquecito, RHNB)

"Ahora las loras ni las algarrobas se dejan. iSe comen todas, no las comen!, las voltean. El chañar que antes se hacía el arrope para los chicos para la tos; antes había mucho... ahora 


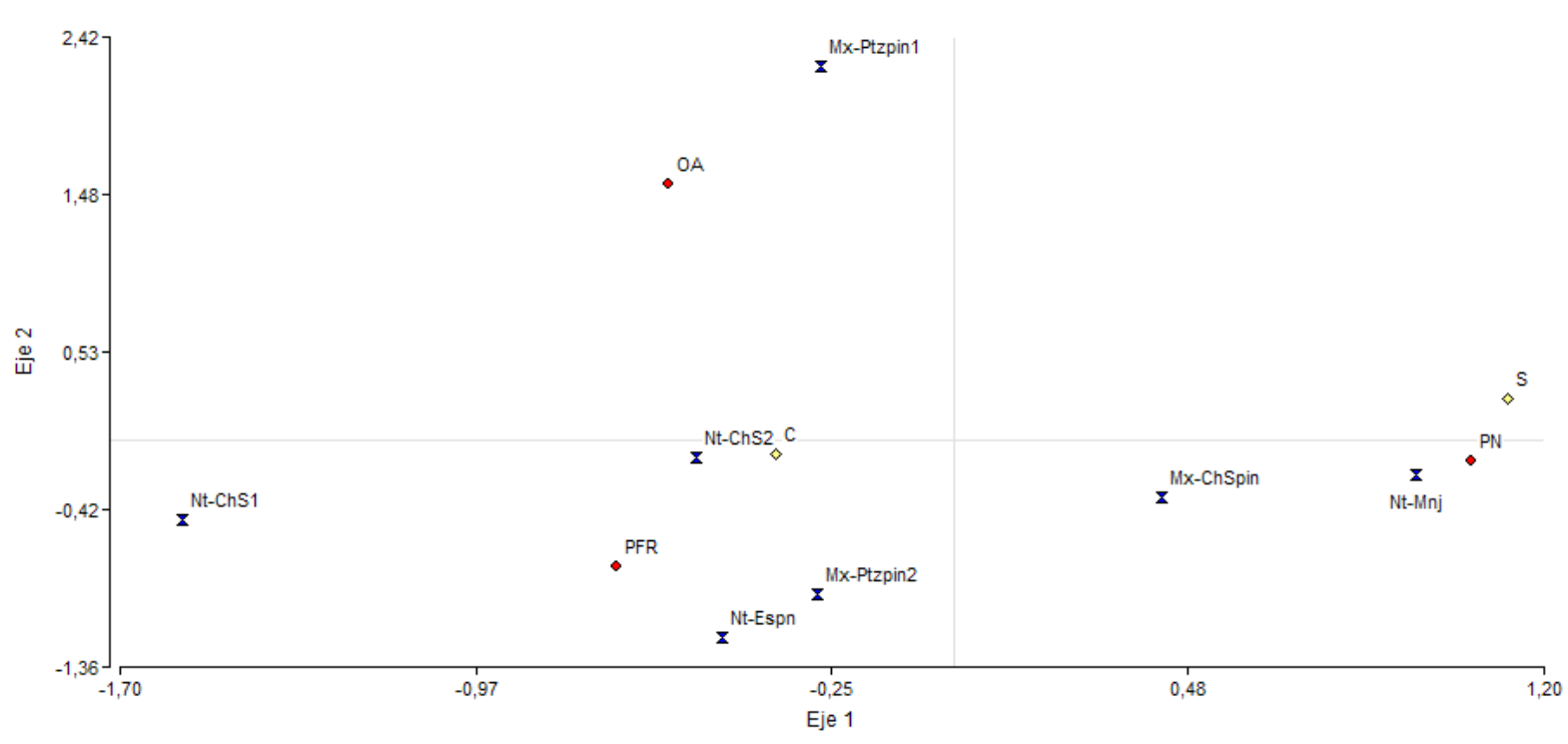

Figura 1. Bi-Plot correspondiente al Análisis de Correspondencia Múltiple entre selección de paisajes (estímulo visual) para vivienda y disfrute (modalidades en reloj), tipos de actores sociales (modalidades en círculos) y perfil socioeconómico (modalidades en rombos). (PN=Población nativa, PFR= Población foránea; $\mathrm{OA}=$ Otros actores; $\mathrm{C}=$ Mayor capital económico; $\mathrm{S}=$ Menor capital económico, presencia de rasgos de economía de subsistencia).

Figure 1. Bi-Plot corresponding to the Multiple Correspondence Analysis between selection of landscapes (visual stimulus) for housing and enjoyment (modalities in clock), types of social actors (modalities in circles) and socioeconomic profile (modalities in rhombuses). (PN = Native population, PFR = Foreign population, $O A=$ Other actors, $C=$ Higher economic capital, $S=$ Lower economic capital, presence of subsistence economy traits).

no dejan nada las loras"

(P., Poblador nativo Villa El Diquecito, RHNB)

En todos los casos anteriormente expuestos se advierte la necesidad de deconstruir la noción de "plaga" o "invasor" en procura de lograr una mejor integración del conocimiento tradicional con las prácticas de conservación de fauna. La aplicación de múltiples perspectivas y disciplinas, permitirá de esta manera minimizar los conflictos existentes entre estos saberes y prácticas (Clark y Primm, 1996).

\section{Análisis cuantitativo de la preferencia de paisajes de ambientes serranos en diferentes actores}

Mediante un análisis de correspondencia se identificaron los criterios de preferencias de paisajes en relación con los diferentes actores. El mismo se aplicó a la consulta acerca del entorno próximo en el que desearía vivir o desarrollar su cotidianeidad y el entorno que modificaría o eliminaría. Para ello se empleó material fotográfico al modo de un estímulo visual, en la que se presentan 8 fotografías, pertenecientes a ambientes diferentes en su composición florística, y fisonómico-visual, involucrando: Vegetación nativa (Nt), como Chaco Serrano (Nt-ChS1, Nt-ChS2) Espinal (Nt-Espn) ambientes con manejo silvopastoril (NtMnj); vegetación Exótica (Ex), como jardines cultivados (Ex-Clt); y mixtos (Mx), como Chaco Serrano con pinares (Mx-ChSpin) y pastizales con pinares (Mx-Ptzpin1, MxPtzpin2). Estas imágenes fueron obtenidas de diferentes regiones o ambientes de áreas serranas no vinculadas con el sitio de residencia del entrevistado. Su implementación procuró dar cuenta de la existencia de criterios y estilos perceptuales más allá de lo declarativo, es decir considerando aspectos interpretativos (sensibilidad, impacto visual, gusto, preferencia, etc.).

En la Figura 1 se observa el gráfico obtenido del Análisis de Correspondencia Múltiple en el que se visualiza las dos dimensiones de la tabla de contingencia que pertenece al cruce de las variables "paisajes para vivir o disfrutar en un entorno próximo", el "tipo de actores sociales" y el perfil socioeconómico. Se puede observar en el primer eje, que se oponen claramente el perfil de la población nativa (PN) respecto de la población foránea (PFR) y los otros actores (OA). Éste último se diferenciaría en el segundo eje del resto de los actores. A su vez la PFR hace una selección amplia de paisajes, más próxima a los de vegetación nativa, como el Espinal o el Chaco serrano (Nt-Esp; Nt-ChS1; Nt-ChS2), aunque también en algunos casos, paisajes mixtos con pinares (Mx-Ptzpin2). Los otros actores (OA) parecieran vincularse en su preferencia a paisajes de pastizales de altura con pinares de estética alpina (Mx-Ptzpin1). Por su parte la población nativa (PN), encontraría mayor afinidad por paisajes nativos que cuentan con algún tipo de manejo silvopastoril (Nt-Mnj), y según el caso, paisajes mixtos de sierras con pinares (Mx-ChSpin).

En la Figura 2 se presenta el gráfico obtenido de otro Análisis de Correspondencia Múltiple, producto esta vez de la interacción entre las categorías de "paisajes para 


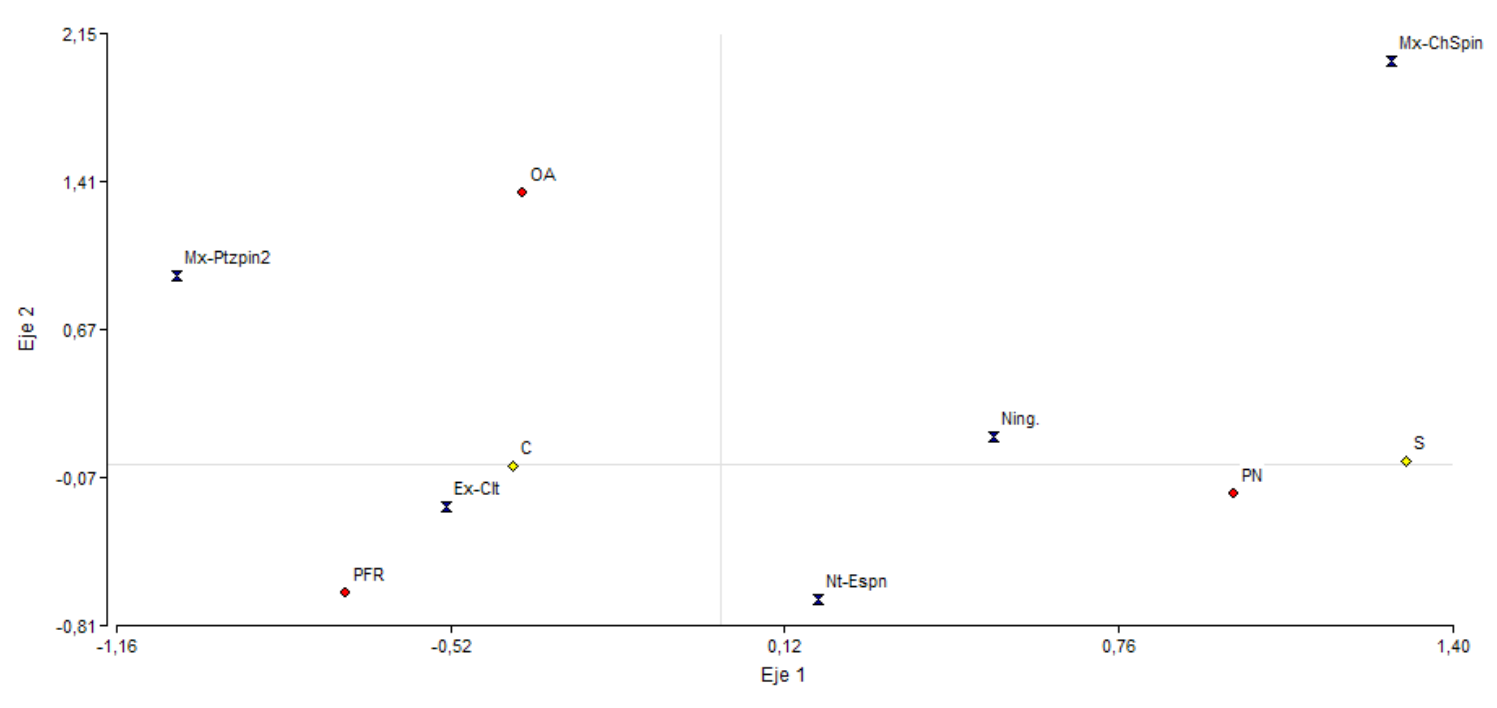

Figura 2. Bi-Plot correspondiente al Análisis de Correspondencia Múltiple entre selección de paisajes (estímulo visual) para modificar o eliminar del entorno (modalidades en reloj), tipos de actores sociales (modalidades en círculos) y perfil socioeconómico (modalidades en rombos). (PN=Población nativa, PFR= Población foránea; $\mathrm{OA}=$ Otros actores; $\mathrm{C}=$ Mayor capital económico; $\mathrm{S}=$ Menor capital económico, presencia de rasgos de economía de subsistencia).

Figure 2. Bi-Plot corresponding to the Multiple Correspondence Analysis between landscape selection (visual stimulus) to modify or eliminate the environment (modalities in clock), types of social actors (modalities in circles) and socioeconomic profile (modalities in rhombuses). (PN = Native population, PFR = Foreign population, $O A=$ Other actors, $C=$ Higher economic capital, $S=$ Lower economic capital, presence of subsistence economy traits).

modificar/eliminar el entorno", los "tipos de actores" y el "perfil socioeconómico". En primer lugar se observa que muchas de las opciones de paisajes presentados en las imágenes no fueron mencionadas en sentido negativo (necesarios de modificación y /o eliminación) por los entrevistados, tal es el caso de Nt-ChS1, Nt-Ch S2 o Nt-Mnj. En relación con las asociaciones consignadas se observa en el primer eje una percepción negativa de la población foránea (PF) y de los otros actores (OA) en relación con los ambientes caracterizados por especies exóticas (Ex-Clt), asi como por los ambientes de pastizales de altura forestados con pinos (Mx-Ptzpin2). En el eje opuesto, la población nativa (PN) se diferencia en su perfil por manifestar la no selección de algunas de las opciones como entorno susceptible de modificación o eliminación (Ning.), -incluso en ningún caso manifestaron rechazo por paisajes exclusivamente exóticos-, el rechazo de ambientes mixtos de Chaco serrano con pinares ( $\mathrm{Mx}$ ChSpin), y aún por algunos ambientes nativos como el espinal (Nt-Espn).

Un aspecto a considerar a modo de síntesis, es que, en ambos análisis de correspondencia realizados las categorías de actores sociales (PN, PF y OA) delimitados en nuestro trabajo, se ubicaron siempre en planos diferentes cuando se consideran ambos ejes de análisis (1 y 2), lo que da cuenta y confirma la existencia de tres modalidades y criterios perceptuales claramente diferenciables entre ellos, siendo en todos los casos el poblador nativo (PN) el que más se distancia respecto de los otros dos (PF y OA).

\section{Síntesis de las percepciones locales}

A partir del material de campo, tanto de las narrativas, como de las encuestas semi-estructuradas y de los análisis cuantitativos, esbozaremos a la manera de una sinopsis de diferentes aspectos de las percepciones locales identificadas en relación con la biodiversidad y su conservación para los tres grupos de actores locales en estudio, a saber:

a) Concepción de hábitat-territorio y aprovechamiento de recursos naturales. En los PN se observa una relación con el hábitat utilitaria, aunque no depredadora. A pesar de que conciben al espacio y sus recursos como "útiles", aprovechables, no por ello justifican prácticas inadecuadas o degradantes, demostrando sensibilidad y criterios para mitigar el impacto de su uso. Entre los $\mathrm{PF}$, en contraste, la relación con el hábitat y territorio es más emocional, estética y de mínima utilidad. Se daría asimismo un comportamiento paternalista, en torno a los recursos naturales con relaciones basadas en la protección y no explotación. Esto iría de la mano con un mínimo aprovechamiento de los recursos naturales (por lo general flora silvestre alimenticia o medicinal, para autoconsumo o tratamientos domésticos basados en "lo natural") o con referencia al valor escénico, espiritual o disfrute del paisaje (e.g., el canto de las aves, la armonía y equilibrio del verde, del agua, etc.). Entre los OA, nos encontramos con un estilo de pensar menos definido y más difuso y heterogéneo, aunque en general más próxima al de los pobladores foráneos. 
b) Vinculación con la biodiversidad: En general y para los tres actores hay un reconocimiento y apropiación de la biodiversidad local del área natural en la que habitan o con la que se vinculan.

- En lo que concierne a la vegetación: Los PN conocen y usan un espectro más amplio de especies nativas. Asimismo son más renuentes a eliminar especies vegetales, conservando aún las especies "exóticas invasoras". Hay aprovechamiento de especies de leña fundamentalmente de especies nativas en función de sus propiedades, poder calorífico y funcionalidad. La recolección sigue un criterio más utilitario, considera sin embargo, recaudos en la extracción. En contraste, los PF y OA conocen un espectro más amplio de especies introducidas, y adoptan una actitud de mayor rechazo $u$ hostilidad hacia éstas. Propician el avance y reforestación con la flora nativa, y no suelen esgrimir ningún tipo de objeción respecto de su rol en los ecosistemas locales. Hay aprovechamiento de leña priorizando especies exóticas locales con una mirada centrada en la conservación y no tan utilitaria.

- Respecto del ganado y fauna silvestre: Para los pobladores ganaderos nativos (PN) los animales obrarían de acuerdo con los principios humanos, entablando por ejemplo relaciones de amigo-enemigo (zorro, puma, cacholote), de patrón-cliente (para los animales domésticos) u otras. Lo que afecta al ganado (e.g., su exclusión en un área protegida), impacta también en su "patrón". Manifiestan una actitud ambigua frente a conservación. Hay especies enemigas y "dañinas" a controlar (ej. puma, zorros); asimismo son conservadores respecto de lo que no afecta a la producción. Para los PF y OA el uso y manejo ganadero se percibe, por lo general, como amenazante del equilibrio ecológico. Resultan más benevolentes con especies que los nativos eventualmente consideran "plagas" o "dañinas" Ej.: cacholote, liebre, zorro. Por otra parte muestran rechazo a especies que no se perciben como problemáticas para los pobladores nativos. Ej. paloma torcaza y paloma doméstica.

c) Visión de problemáticas ambientales relacionadas con la biodiversidad local: Los PN no perciben problemáticas que devienen de complejos procesos ecológicos o cambios ecosistémicos y que no afectan visiblemente a la actividad productiva (e.g., invasiones de especies exóticas). Respecto de las invasiones biológicas las concepciones de "invasión/invasor" se aplican tanto para flora exótica (acacia negra) como también para especies nativas (tuscales, espinillares) que afectan las actividades domésticas (cría de ganado, recolección en bosques). Resulta habitual que algunas especies listadas en contextos académicos como "invasoras" presentan una valoración no desdeñable por sus aplicaciones etnobotánicas (sombra, disfrute, ornamentación). En contraposición, los PN y OA perciben problemas ambientales vinculados con procesos ecológicos no siempre visibles, (e.g. la relación entre déficit hídrico y erosión del suelo, o por avance de especies invasoras). Especificamente en relación con las invasiones biológicas enfatizan la necesidad de control de especies vegetales exóticas como paraíso (Melia azedarach), acacia negra (Gleditsia triacanthos), crataegus (Pyracantha spp), siempre verde (Ligustrum lucidum) con argumentaciones vinculadas al mayor consumo de agua en relación con la flora nativa. Asimismo promueven la propagación o conservación de los recursos nativos.

d) Percepción del paisaje (a través de estímulo visual): Entre los PN se da una proximidad afectiva e interés en los paisajes con manejo silvo-pastoril; asimismo cobra importancia la presencia de un animal en el sitio escogido para vivir y trabajar. Los PF y OA muestran una diversidad y amplitud de opiniones: Por un lado la preferencia por ambientes de vegetación nativa como el Chaco Serrano, en menor medida del Espinal. Por el otro, un rechazo hacia los ambientes conformados exclusivamente por plantas exóticas y una aceptación dispar de paisajes mixtos de pastizales con forestación de pinares.

e) Concepción, actitud y protagonismo frente a la conservación: Entre los PN la conservación viene de la mano con la posibilidad de mantener prácticas culturales de aprovechamiento de los recursos del entorno. Por otra parte el protagonismo es escaso o pasivo en actividades de conservación y gestión de la conservación. Tanto los PF como los OA, en tanto, muestran una participación activa en torno a la planificación, manejo o reglamentación de un área protegida. La PF promueve la conservación de lo prístino-en especial de la biodiversidad autóctona- con pretensiones de intangibilidad o de transformaciones mínimas. Entre los OA algunos adquieren un rol de modeladores de opinión, generadores de cambio y protagonistas de tareas educativas o que procuran la sustentabilidad local.

\section{Discusión de cierre}

A lo largo de éste estudio, y respondiendo una de nuestras preguntas de trabajo, fue posible identificar estilos de percepción diferentes en función de los actores sociales vinculados a la práctica de la conservación de estas áreas protegidas. Éstos se hicieron particularmente distintivos entre los pobladores nativos (campesinos o descampesinizados, por lo general con un menor capital económico) respecto al de los pobladores neorrurales y, en menor medida, al de otros actores externos. Nuestros análisis cuantitativos multivariados resultan en la misma dirección $y$, al igual que las preferencias o gustos que plantea Bourdieu (2012), damos cuenta cómo el campo de lo ambiental y su conservación, revela posiciones sociales asociadas a diferentes "trayectorias" y "estilos de vida" que a su vez, se expresan en modos diferentes de percibir el paisaje serrano.

Asimismo, vemos cómo las percepciones ambientales se manifiestan, según la acepción de Fernández-Moreno (2008), en formas diferentes en las que los actores aprecian, valoran, interpretan, se vinculan y/o modifican 
su entorno. Estos podemos comprenderlos también como "estilos de pensar" la biodiversidad y su conservación, al hacer uso de la expresión de Douglas (1998), o para el caso, haremos la transposición a los estilos de percepción. Consideramos oportuna, la sugerencia de Durand (2008) de incorporar a la percepción, la noción de "interpretación ambiental", al resaltar que las acciones y vivencias forman parte de la experiencia de los individuos y a la vez, resultan de suma importancia en la conformación de las percepciones sobre la naturaleza.

Se advierte que, en la percepción de los "poblador nativos", no resultan centrales para la tarea de conservación aquellas problemáticas que devienen de complejos procesos ecológicos o cambios ecosistémicos y que no afectan o atañen, al menos en forma tan visible o directa, a la actividad productiva (e.g., invasiones de especies exóticas). Las sequías y disminución de caudal de cursos de agua, por ejemplo, son percibidas por ellos como meras contingencias climáticas, y en contadas ocasiones la relacionan directamente a la pérdida de masa boscosa. Asimismo, el término "invasiones" o el calificativo de "invasivo" los emplean con menor frecuencia que los pobladores foráneos u otros actores, a la vez que adoptan connotaciones diferentes, toda vez que se emplean a veces, para referir la flora exótica (acacia negra) y otras, para las plantas nativas que conforman comunidades monoespecíficas o abundantes (tuscales, espinillares) que dificultan la actividad humana (ganadería, recolección en bosque, etc). Asimismo, vemos cómo algunas especies listadas en contextos académicos como "invasoras" presentan una valoración etnobotánica no desdeñable, por las aplicaciones y los servicios ecosistémicos que éstos proveen (sombra, disfrute, ornamentación). Como lo señalan Sagie et al. (2013) en relación con un estudio de percepción local de los servicios ecosistémicos provistos por los desiertos de israelitas-jordanos, es posible que éstos se encuentren subdimensionados o, para el caso, sólo percibidos desde la perspectiva de los actores externos no campesinos. A manera de síntesis, para estos actores el modelo de conservación está estrechamente vinculado a la posibilidad de aprovechamiento y uso de la biodiversidad local, esto es, se valora y practica la conservación de lo que resulta útil.

En contraste con la población nativa, el estilo de percepción de los "pobladores foráneos", con mayor capital económico, enfoca la tarea de conservación en la menor intervención posible, o sólo en la necesaria para garantizar procesos ecológicos que lo mantienen o reconstituyen. Asimismo, resultan recurrentes las representaciones acerca de conservación de lo prístino-en especial de la biodiversidad autóctona-, las pretensiones de intangibilidad o de transformaciones mínimas, en las que el uso y manejo ganadero se percibe, por lo general, como amenazante del equilibrio ecológico. Las medidas de control se remiten casi exclusivamente sobre especies exóticas, invasoras, o plaga, promoviendo el impulso y la propagación o conservación de los recursos nativos. En particular entre la población neorrural de La Rancherita, las entrevistas enfatizan la necesidad de control de especies vegetales exóticas invasoras. Resultan asimismo más benevolentes con especies que los nativos eventualmente consideran plagas o dañinas. A diferencia de la población nativa, y probablemente debido a un proceso formal de instrucción más consolidado, perciben problemas ambientales vinculados con procesos ecológicos no siempre visibles, como la relación entre déficit hídrico y el avance de especies invasoras. En resumen, la conservación para estos actores, se encuentra en relación con una percepción más romántica y proteccionista del ambiente local. Siguiendo la caracterización de Descola y Pãlsson (2001), estaríamos en presencia de una relación humanoambiente de tipo paternalista, que considera el dominio del hombre sobre los recursos naturales a través de su protección y de su no explotación.

El estilo de percepción de los "otros actores" resulta menos definido y más heterogéneo, aunque en general más próxima al de los pobladores foráneos. Particularmente diferente es la de aquellos entrevistados que participan del cuidado del ambiente o se vinculan profesionalmente al mismo. En este sentido, es interesante señalar cómo algunos de estos actores -en ocasión portadores de saberes ecológicos académicos- adquieren un rol de modeladores de opinión, generadores de cambio y protagonistas de tareas educativas o de otra índole que procuran la sustentabilidad local. Asociados en muchos casos a las actividades de ONGs, éstas dependen en gran medida de la división occidental entre naturaleza y cultura, presentando a la primera como objeto estático separado de los seres humanos (West et al. 2006).

El presente estudio da cuenta entonces, y tal como lo señalan Seidi et al. (2011), de la existencia de una heterogeneidad entre grupos y aún dentro de un mismo grupo cultural. De allí que proponemos profundizar más su estudio y análisis, detallando las diferentes visiones en la heterogeneidad de los entrevistados.

Tal como lo señala Arach (2002), los actores a los que nos referimos son "sujetos socialmente ubicados y culturalmente construidos, y sus posicionamientos también reflejan carga de sentido heredada, haciendo que nociones nominalmente similares (desarrollo sustentable, biodiversidad, etc.) puedan adquirir significados diferenciables para cada uno de ellos". Los mismos se encuentran atravesados por la diversidad de trayectorias de los informantes, por el nivel educativo, por la adscripción socioeconómica, y/o por la mayor o menor vigencia de conocimientos, usos y prácticas en relación con la biodiversidad. En suma, las percepciones sobre el ambiente y la conservación se encuentran arraigadas en una particular cosmovisión respecto de la relación naturaleza y cultura, en la que por lo general se ubica a la sociedad por fuera de la naturaleza. Al decir de West et al. (2006) las áreas protegidas se han convertido cada vez más en los medios por los cuales muchas personas 
ven, entienden, experimentan y usan la parte del mundo conocidos habitualmente como naturaleza y ambiente. Esta visión ha impuesto la dicotomía naturaleza/ cultura en espacios y gente en los que la distinción entre naturaleza y cultura no existía previamente. De esta manera, las áreas protegidas han devenido en una nueva cosmología de lo natural, una forma de ser y estar en el mundo. La conformación de áreas protegidas, al producir una idea de naturaleza para un territorio específico genera cambios económicos, sociales y políticos en los que el conflicto pasa a ser el corazón de su establecimiento, en parte porque los enfoques no han sabido apreciar o trabajar con las prácticas o intereses locales. La antropología de las áreas protegidas debería enfocar la construcción de puentes entre la atención sobre los impactos de la economía política de la globalización, y los efectos sociales a nivel local. En este sentido, la comprensión y análisis de las percepciones locales resultan necesarios, toda vez que las áreas protegidas van siendo consideradas como territorios que deben resguardar el patrimonio natural y cultural y no sólo el de la biodiversidad, y a la vez asegurar la provisión de servicios ambientales en orden a un desarrollo sostenible.

Finalmente haremos referencia a Durand (2008) que retoma a Ingold (2000), al considerar que la percepción es acción, dando cuenta del corto trecho existente entre percepción y actitud ambiental. Este aspecto se pone de manifiesto, por ejemplo, en cómo un ambiente nuevo, transformado, es el contexto en el que los sujetos por ejemplo nuevas generaciones de las poblaciones descampesinizadas frente a la modernidad- generan nuevos saberes, y en simultáneo, una actitud de desinterés y desafectación por los conocimientos, usos locales y conservación de la flora y fauna nativa. Esto nos pone de cara a revisar, junto a los actores locales, nuestro modo de concebir las relaciones humano-ambiente, de manera de producir orientaciones de manejo y políticas más sensibles al saber práctico y a la etnografía, atento a que es en la actitud ambiental donde se ancla y evidencia una práctica apropiada de conservación.

Córdoba, 16 de marzo de 2016

\section{Agradecimientos}

A la Dra. Natalia Bermúdez por sus sugerencias y comentarios y facilitar bibliografía antropológica. Los autores agradecen a CONICET por sustentar la labor de investigación. El trabajo fue desarrollado en el marco de los proyectos PICT 1001 y PICT 1633. Agradecemos especialmente la colaboración de las personas vinculadas a la Reserva Hídrica y Recreativa Bamba, la Reserva Comunal La Rancherita y el Parque Nacional Quebrada del Condorito por habernos compartido sus saberes y experiencias.

\section{Bibliografía}

Anderson, E.N., D. M. Pearsall, E. S. Hunn \& N. J. Turner, eds. (2011). Ethnobiology, 12:189-212, Wiley-Blackwell, N. J. Hoboken, New Jersey.
Arach, O. (2002). Ambientalismo, desarrollo y transnacionalidad en Paraguay. Consideraciones a partir de las protestas sociales en torno de la represa de Yaciretá. Cuadernos para el Debate, 16: 5-46.

Bardsley, D., Edwuards-Jones, G. (2006). Stakeholder's perceptions of the impacts of insasive, GeoJournal, 65: 199-210.

Barri, F. (2012). Territorio, percepción ambiental e intereses en conflicto: El caso de la Reserva Vaquerías. Facultad de Filosofía y Humanidades, Universidad Nacional de Córdoba, Argentina. Tesis de Especialidad en Antropología. Repositorio de tesis de antropología FFyH, UNC.

Berkes, F., J. Colding \& C. Folke. (2000). Rediscovery of Traditional Ecological Knowledge as Adaptive Management. Ecological Applications, 10 (5): 1251-1262.

Berkes, F. (2011). (Ed.) Sacred ecology: traditional ecological knowledge and resource management, Taylor y Francis, New York. pp. 363.

Bourdieu, P. (2012). La distinción. Crítica social del gusto, Taurus, Madrid. pp. 784.

Cabrera, A. L. (1994). Regiones fitogeográficas argentinas. Enciclopedia Argentina de Agricultura y Jardinería, Tomo 2, Fascículo 1. Acme S.A.C.I., Buenos Aires. pp. 85.

Cáceres, D., G. Soto, G. Ferrer, F. Silvetti \& C. Bisio. (2010). La Expansión de la Agricultura Industrial en Argentina Central. Su Impacto en las Estrategias Campesinas. Cuadernos de Desarrollo Rural 7(64): $91-119$.

Cingolani, A.M., I- Noy-Meir, D. Renison \& M. Cabido. (2008). La ganadería extensive ¿es compatible con la conservación de la biodiversidad y de los suelos? Ecología Austral, 18: 253-371

Clark T.W. \& Primm S.A. (1996). Making sense of the policy process for carnivore conservation, Conservation Biology, 10: $1036-1045$.

Cunningham, A. B. (2001). Etnobotánica aplicada. Pueblos, uso de plantas silvestres y conservación. Nordan-Comunidad, Montevideo. pp. 310.

Descola, P. \& G. Pálsson. (2001). Naturaleza y Sociedad. Perspectivas antropológicas, Siglo XXI, México D.F. pp. 360.

Douglas, M. (1998). Estilos de Pensar, Gedisa, Barcelona. pp. 213.

Durand, L. (2008). De las percepciones a las perspectivas ambientales. Una reflexión teórica sobre la antropología y la temática ambiental. Nueva Antropología XXI (68): 75-88.

Fernández, M., C. Flores-Pedrero \& G.J. Martínez. (2013). Diagnóstico participativo, orientaciones y aportes para la gestación y reglamentación de una reserva de usos múltiples en la comuna de La Rancherita, Informe Técnico. Museo de Antropología. Universidad Nacional de Córdoba, Argentina.

Fernández-Moreno, Y. (2008). ¿Por qué estudiar las percepciones ambientales? Una revisión de la literatura mexicana con énfasis en Áreas Naturales Protegidas, Estudios sobre Estado y Sociedad XV (43): 179-202. 
Gavier, G. y E.H. Bucher. (2004). Deforestación de las Sierras Chicas de Córdoba (Argentina) en el periodo 1970-1997. Academia Nacional de Ciencias, Miscelánea 101:1-27.

Glaser, B. y A. Strauss, (1967). The Discovery of Grounded Theory. Strategies for Qualitative Research, Aldine Publishing Company, New York. pp. 271.

Ingold, T. (2000). The perception of the environment. Essays on livelihood, dwelling and skill, Routledge, London and New York. pp. 463.

Jaquenod De Zsögön, S. (2014). Antropología Ambiental. Conflictos por recursos naturculturales y vulnerabilidad de poblaciones, Dykinson, Madrid. pp. 403.

Ladio, A.H. (2013). Soluciones locales y flexibilidad en el conocimiento ecológico tradicional frente a procesos de cambio ambiental: estudios de caso en Patagonia. Ecología Austral, 23: 184-193.

Ladio, A. H., S. Molares, J. Ochoa, B. Cardoso. (2013). Etnobotánica aplicada en Patagonia: la comercializacion de malezas de uso comestible y medicional en una feria urbana de San Carlos Bariloche (Río Negro, Argentina). Boletín Latinoamericano y del Caribe de Plantas Medicinales y Aromáticas-BLACPMA , 12 (1): 24-37.

Le Breton D. (2012). Por una antropología de las emociones. Revista Latinoamericana de Estudios sobre Cuerpos, Emociones y Sociedad-RELACES, 10:67-77.

Lichtenstein, G., P. Carmanchahi. (2014). Hilando sueños: una experiencia de conservación y desarrollo local. Avá. Revista de Antropología, 24: 161-181.

Manzano-García, J. 2013. "Valoración de las prácticas de conservación ambiental en áreas protegidas de las Sierras de Córdoba desde la percepción de sus actores locales". Facultad de Ciencias Exactas, Físicas y Naturales, Universidad Nacional de Córdoba, Argentina. pp. 172. Tesis de Maestría en Manejo de Vida Silvestre. Centro de Zoología Aplicada.

Ojasti L. (1984). Hunting and conservation of mammals in Latin America, Acta Zool. Fennica, 172: 177 - 181.

Ojeda, M.S. y U.O. Karlin: (Eds.) G.J. Martinez, Y. Massuh, S. Ocaño, L. E. Torres, A. G. Chavez, O. Arizio, A. Urioni. (2015). Plantas aromáticas y medicinales. Modelos para su domesticación, producción y usos sustentables, Edit. Universidad Nacional de Córdoba, Córdoba. pp.183.

Palacios, A. A., J.M. Spicogna, J. Bernasconi, I. Budini, S. Rufini, Y. Ferreyra, E. Salguero y D. Díaz. (2010). Decidirnos a decidir. Experiencias sobre la gestación de la Unidad Reserva Natural Militar la Estancia La Calera y Reserva Hídrica y Recreativa Natural Bamba, Aula de Montaña de la Universidad Nacional de Córdoba, Argentina.

Richeri, M., A. H. Ladio, A. M. Beeskow. (2012). Conocimiento tradicional y autosufciencia: la herbolaria rural en la Meseta Central del Chubut (Argentina), Boletín Latinoamericano y del Caribe de Plantas Medicinales y Aromáticas-BLACPMA, 12:4858.
Richeri, M., M. B. Cardoso. Rist S. y F. Dahdouh-Guebas. (2006). Ethnosciences--A step towards the integration of scientific and indigenous forms of knowledge in the management of natural resources for the future, Environment, Development and Sustainability, 8(4): 467-493.

Sagie H., A. Morris, Y. Rofé, D. Orenstein y E. Groner. (2013). Cross-cultural perceptions of ecosystem services: A social inquiry on both sides of the Israeli-Jordanian border of the Southern Arava Valley Desert, Journal of Arid Environments, 97: 38-48.

Santamarina-Campos, B. y J. Bodí. (2012). Lugares rurales versus espacios naturalizados. Conocimientos y reconocimientos en las lógicas patrimoniales de las áreas protegidas, Revista de Antropología Iberoamericana -AIBR, 8 (1): 111-138.

Seidi G.U., H. Morales, L.A. Arriola-Vega y A.A. Evangelista-García. (2011). "Ya no hay árboles ni agua". Perspectivas de los cambios ambientales en comunidades de Zinacatán, Chiapas, LiminaR. Estudios sociales y humanísticos IX (1): 98-119.

Sillero C. (2000). Editorial sobre resolución de conflictos entre los grandes carnívoros y el hombre, Mastozoología Neotropical, 7 (2): $69-72$.

Suárez, M.E. (2014). Etnobotánica wichí del bosque xerófito en el Chaco Semiárido salteño. Don Torcuato, Buenos Aires, Argentina. pp. 522.

Torrella S. y J. Adámoli. (2005). Situación ambiental en el Chaco Árido y Serrano En A. Brown, U. Martínez Ortiz, M. Acerbi y J. Corchera J (eds). La Situación Ambiental Argentina. pp. 75-83, Fundación Vida Silvestre Argentina, Buenos Aires.

Trillo, C; S Colantonio y L. Galetto. (2014). Perceptions and use of native forests in the arid Chaco of Córdoba, Argentina. Ethnobotany Research and Applications, 12:497-510.

Trillo, C., B. Arias-Toledo, S. E. Colantonio. (2016). Uso y percepción del bosque por pobladores de diferente tradición cultural de la Laguna de Mar Chiquita, Córdoba, Argentina. Ecología Austral, 26:7-16.

West, P., J. Igoe, D. Brockington. 2006. Parks and peoples: the social impact of protected áreas. Annual Review of Anthropology, 35: 251- 277 .

Trimano, L. (2015). Integración social y nueva ruralidad: ser ¿"hippie"? en el campo. Revista de Antropología Social, 24: 317-348.

Wiersum, K. F. (1997). Indigenous exploitation and management of tropical forest resources: an evolutionary continuum in forestpeople interactions, Agriculture, Ecosystems \& Environment, 63(1): 1-16.

Zak, M., M. Cabido y J. Hodgson. (2004). Do subtropical seasonal forests in the Gran Chaco, Argentina, have a future? Biological Conservation, 120: 589-598.

Zak, M., M. Cabido, D. Cáceres y S. Díaz. (2008). What drives accelerated land cover change in central Argentina? Synergistic consequences of climatic, socio-economic and technological factors, Environmental Management, 42(2): 181-189. 
Anexo - Listado de especies vegetales y animales mencionadas en las narrativas

\begin{tabular}{|c|c|}
\hline Nombre común & Especie vegetal \\
\hline Acacia negra & Gleditsia triacanthos \\
\hline Algarrobo blanco & Prosopis chilensis \\
\hline Cabotoril & Hypericum connatum \\
\hline Canchalagua & Scoparia montevidensis \\
\hline Carqueja & Baccharis articulata \\
\hline Carquejilla & Baccharis crispa \\
\hline Chañar & Geoffroea decorticans \\
\hline Coco & Zanthoxylum coco \\
\hline Cola de quirquincho & Phlegmariurus saururus \\
\hline Contrahierba & Trixis divaricata subsp. discolor \\
\hline Crataegus & Pyracantha spp. \\
\hline Diente de león & Taraxacum officinale \\
\hline Doradilla & Anemia australis \\
\hline Espinillo & Acacia caven \\
\hline Hierba del carnicero & Conyza bonariensis \\
\hline Hierba del sapo & Marrubium vulgare \\
\hline Higuerilla & Broussonetia papyrifera \\
\hline Hongo de coco, de molle & Phlebopus bruchii \\
\hline Lirio acuatico & Iris pseudacorus \\
\hline Manzano de campo & Ruprechtia apetala \\
\hline Matapulga & Schkuhria pinnata \\
\hline Molle & Lithraea molleoides \\
\hline Mora & Morus spp. \\
\hline Olmo & Ulmus sp. \\
\hline Paico & Dysphania ambrosioides \\
\hline Palo amarillo & Aloysia gratissima \\
\hline Paraiso & Melia azedarach \\
\hline Peperina & Minthostachys mollis \\
\hline Piquillin & Condalia buxifolia \\
\hline Pulmonaria & Croton subpannosus \\
\hline Quebracho blanco & Aspidosperma quebracho-blanco \\
\hline Quiebrarado & Heimia salicifolia \\
\hline Romero & Rosmarinus officinalis \\
\hline Ruda & Ruta chalepensis \\
\hline Siempre Verde & Ligustrum lucidum \\
\hline Suico & Tagetes minuta \\
\hline Tomillo serrano & Hedeoma multiflora \\
\hline Tusca & Acacia aroma \\
\hline Verdolaga & Portulaca oleracea \\
\hline
\end{tabular}


Anexo - Listado de especies vegetales y animales mencionadas en las narrativas

\begin{tabular}{|c|c|}
\hline Nombre común & Especie animal \\
\hline Aguila mora & Geranoaetus melanoleucus \\
\hline Bigua & Phalacrocorax brasilianus \\
\hline Brasita & Coryphospingus cucullatus \\
\hline Cacholote & Pseudoseisura lophotes \\
\hline Calandria & Mimus triurus \\
\hline Carpa & Cyprinus carpio \\
\hline Carpintero real & Colaptes melanolaimus \\
\hline Chalchalero & Turdus amaurochalinus \\
\hline Chancho de monte & Tayassu tajacu \\
\hline Cóndor & Vultur gryphus \\
\hline Jilguero & Sicalis flaveola \\
\hline Lora & Myiopsitta monachus \\
\hline Mojarrita & Bryconamericus iheringi \\
\hline Moncholo & Pimelodus albicans \\
\hline Paloma común & Columba livia \\
\hline Paloma torcaza & Zenaida auriculata \\
\hline Palometa & Australoheros facetus \\
\hline Pejerrey & Odontesthes bonariensis \\
\hline Puma & Puma concolor \\
\hline Semillero & Sporophila caerulescens \\
\hline Tararira & Hoplias malabaricus \\
\hline Trucha arcoiris & Oncorhynchus mykiss \\
\hline Trucha de arroyo & Salvelinus fontinalis \\
\hline Zorro & Pseudalopex griseus \\
\hline Zorzal & Turdus chiguanco \\
\hline
\end{tabular}

